\title{
People are different: tyrosine's modulating effect on cognitive control in healthy humans may depend on individual differences related to dopamine function
}

\author{
Bryant J. Jongkees, Bernhard Hommel and Lorenza S. Colzato* \\ Institute of Psychological Research and Leiden Institute for Brain and Cognition, Leiden University, Leiden, Netherlands \\ ${ }^{*}$ Correspondence: colzato@fsw.leidenuniv.nl \\ Edited by: \\ Mattie Tops, VU University Amsterdam, Netherlands \\ Reviewed by: \\ Dimitri Van Der Linden, Erasmus University Rotterdam, Netherlands
}

Keywords: tyrosine, cognition, dopamine, individual differences, genetics

\section{INTRODUCTION}

The amino-acid tyrosine (TYR) is thought to modulate cognitive functions that are driven by dopamine (DA), as consumption of TYR enhances DA levels in the brain (Gibson and Wurtman, 1977; Cuche et al., 1985). It could therefore reverse decreases in DA level that are detrimental for cognitive performance (Muly et al., 1998; Goldman-Rakic et al., 2000; Nieoullon, 2002). So far, TYR has been considered not so much as an enhancer of healthy cognitive functioning but rather as a means to reduce the negative side-effects of dopamine-related pathologies, such as Parkinson's disease (Growdon et al., 1982; Lemoine et al., 1989), phenylketonuria (van Spronsen et al., 1996), depression (Gelenberg and Gibson, 1984), and attention deficit hyperactivity disorder (Wood et al., 1985). However, the outcomes were mixed: some patients reported significant improvements, while other did not. In clinical samples some variation in response may be explained by impaired processes such as DA synthesis, which would lessen or even completely prevent an effect of TYR. But even healthy samples differ in response to TYR supplementation, which suggests that clinically impaired DA function is not the only source of variation.

The focus of the present opinion article is not on clinical populations but on TYR effects on cognitive control in healthy humans. In healthy individuals, TYR has often been used to reduce the negative effects of conditions that deplete the brain's dopaminergic resources, such as extreme stress. The supply of TYR was found to reduce stress-induced impairments of working memory and attentional tasks, but more so in individuals who were particularly sensitive to the stressors (Deijen and Orlebeke, 1994; Shurtleff et al., 1994; Mahoney et al., 2007). Even without exposure to stress, administration of TYR has been shown to have an acute beneficial effect on taskperformance thought to be related to DA, e.g., simultaneously performing multiple tasks (Thomas et al., 1999), the updating and monitoring of working memory (Colzato et al., 2013a), and inhibitory control (Colzato et al., 2014a). Taken together, in healthy humans TYR seems to work against what has been coined "ego-depletion"- the exhaustion of limited cognitive control (CC) resources (Baumeister et al., 1998). Demanding tasks may deplete the available control resources more, especially in individuals having fewer resources and/or those that suffer more from the situational demands, and TYR may be able to replete the missing resources to some degree. This possibility should not be surprising given that CC relies on DA (Cools, 2006). The hypotheses that DA is one of the depleted resources and TYR reverses its depletion are consistent with the idea that there is an optimal level of DA at which cognitive performance peaks while it suffers at lower levels (Muly et al., 1998; Goldman-Rakic et al., 2000; Nieoullon, 2002). Given that TYR raises the DA level, we argue that TYR can enhance cognitive performance in healthy individuals whenever one has a lower than optimal DA level.

Besides individual differences in the response to task-induced depletion, DA level also seems to vary between healthy individuals in a more stable and enduring fashion (Cools, 2006; Cools et al., 2008, 2009). This suggests that individuals differ in how far away they are from their optimum, i.e., some individuals have a lot of room for improvement, while others may already have an optimal, or even a higher-than-optimal DA level. We expect that individuals with an optimal baseline have little left of the enzyme called tyrosine-hydroxylase, which converts TYR into DA (Daubner et al., 2011). This means that they have little risk of overdosing from TYR supplementation, instead they should experience hardly any change in performance.

Given that individuals can vary in their response to TYR supplementation, it is necessary that future studies on TYR take into account individual differences, so to ensure that samples are comparable and results are generalizable. To this end we discuss a number of DA-related measures and factors that could predict or modulate the effect of TYR supplementation. This is by no means an exhaustive list; the aim of this opinion article is rather to point out and highlight some accessible predictors of DA function that may help to improve designing future TYR studies and making the analyses of their outcomes more informative. To this date, the individual differences discussed below have not yet been investigated in combination 
with TYR. However, based on literature that details their relation to DA function we argue that these individual differences will prove fruitful for future research.

\section{INDICATORS AND MODULATORS OF DA FUNCTION}

At present, DA can only be measured (relatively) directly using positron emission tomography (PET), which is rather expensive and invasive as it involves injecting a radioactive substance into the bloodstream (Volkow et al., 2009). Noninvasive and cheap alternatives to estimate DA function exist, and some can be found in our eyes. The amacrine and interplexiform cells of the retina contain a high concentration of DA (Bodis-Wollner and Tzelepi, 1998; Witkovsky, 2004), and disorders associated with DA dysfunction have been related to abnormal color discrimination (Pieri et al., 2000; Tannock et al., 2006; Hulka et al., 2013). It has been proposed that deficits in color vision, particularly blue-yellow impairment, indicate a central hypodopaminergic state (Roy et al., 2003). This proposition is consistent with the recent finding that color discrimination predicts cognitive control, with better discrimination being associated with more efficient conflict-resolution in an auditory Simon task (Colzato et al., 2014b). Given the relation between color vision and DA level, we argue that color vision can predict the effect of TYR supplementation. Particularly individuals with impaired color vision could benefit from TYR, as they are likely to have less DA than non-impaired peers.

Another interesting aspect of our eyes is the spontaneous eye blink rate (EBR), which has been found to reliably indicate the striatal DA level (Karson, 1983). Specifically, a higher EBR is associated with more striatal DA. As expected, disorders related to abnormal DA function show atypical EBRs: Parkinson's disease is associated with decreased DA levels, and correspondingly with decreased EBRs (Deuschel and Goddemeier, 1998), while schizophrenia is associated with increased DA levels and increased EBRs (Freed, 1980). Also, EBR has been successfully used to predict individual differences in cognitive performance (e.g., Dreisbach et al., 2005; Colzato et al., 2007b, 2008a,b, 2009). Given the relation between DA and EBR, it follows that EBR can predict the benefit of TYR supplementation. We suggest that individuals with a low EBR, indicative of a low DA level, stand to benefit most from TYR, as it will bring their DA level closer to the optimum that is associated with peaking performance (Muly et al., 1998; Goldman-Rakic et al., 2000). Of further interest, striatal DA is thought to be particularly involved in cognitive flexibility (Cools, 2006) — the ability to update and switch between mental representations (Miyake et al., 2000). Therefore, EBR might predict improvement in performance especially on tasks that require a flexible mind.

Moving on to gene polymorphisms, the Val158Met-polymorphism in the catecholO-methyltransferase (COMT) gene could also predict the effect of TYR supplementation, as this gene is involved in DA degradation in the prefrontal cortex. Specifically, the Met allele is associated with slower degradation of DA and high levels of prefrontal DA as the result, whereas the Val allele is associated with faster DA degradation and less prefrontal DA (Chen et al., 2004). As expected, several studies have shown Val-carriers to be less adept at cognitive tasks than Metcarriers (Egan et al., 2001; Mattay et al., 2003; Goldberg and Weinberger, 2004), which suggests that Val-carriers have lesser DA. This again implies that Val-carriers stand to benefit from TYR supplementation. Of further interest is the fact that prefrontal DA is tightly associated with cognitive stability (Cools, 2006), i.e., the ability to maintain task-relevant representations in the face of distractors or interference (Miyake et al., 2000). Given that the COMT gene modulates prefrontal DA level, its polymorphism could predict improvement especially on tasks that require cognitive stability.

Another candidate for modulating the effect of TYR supplementation is the C957T polymorphism in the DRD2 gene, which is linked to messenger RNA stability (Duan et al., 2003), leading to variation in extrastriatal D2 receptor availability (Hirvonen et al., 2009a) and striatal DA level (Hirvonen et al., 2009b). Specifically, T-carriers have reduced messenger RNA stability, which results in less striatal DA than homozygotic Ccarriers. Correspondingly, T-carriers show less inhibitory control (Colzato et al., 2010, 2013b) and worse memory performance (Li et al., 2013). Also related to striatal DA is a second gene called DAT1, which is involved in DA reuptake (Lewis et al., 2001). Although there have been contradictory findings on how the varying number of base pair repeats in this gene relates to DA transporter (DAT) availability, recent studies suggest that 10 -repeat homozygotes have lesser DAT availability, and consequently more striatal DA, than 9-repeat carriers (van de Giessen et al., 2009; Shumay et al., 2011). This is consistent with the finding that 10 -repeat carriers are better than 9-repeat carriers at updating stimulus-response bindings (Colzato et al., 2013c), which is thought to be driven by DA (Colzato et al., 2007a,b). Given that both T-carriers of the DRD2 gene and 9-repeat carriers of the DAT1 gene are likely to have less striatal DA, we argue that especially they can benefit from TYR supplementation, again perhaps more so on tasks that require flexible cognition.

Interestingly, the aforementioned effect of the DRD2 polymorphism on inhibitory control and memory performance is stronger in older individuals than in younger ones (Colzato et al., 2013b; Li et al., 2013). This is consistent with the resource-modulation hypothesis (Lindenberger et al., 2008), which states that aging-related changes in neurophysiology enlarge the effect of polymorphisms on cognition. Given that DA systems deteriorate with old age (Volkow et al., 1998; Bäckman et al., 2000, 2006; ErixonLindroth et al., 2005), it is important to take characteristics such as age into consideration when investigating the modulating effect of TYR on DA and cognitive functions.

Last but not least is the tyrosinehydroxylase $(\mathrm{TH})$ gene, which codes for the enzyme that converts TYR into L-DOPA (Daubner et al., 2011). The C824T-polymorphism in the $\mathrm{TH}$ gene has been shown to influence urinary excretion of norepinephrine, with carriers of the $\mathrm{T}$ allele excreting more norepinephrine (Rao et al., 2007). Horiguchi et al. (2014) found that in patients with schizophrenia the $\mathrm{T}$ allele is associated with increased $\mathrm{TH}$ transcription activity and higher IQ. These authors proposed that the resulting 
increase in norepinephrine levels in the brain may have protected the patients from cognitive decline. Higher levels of norepinephrine suggest higher levels of DA as well, since DA is the precursor of norepinephrine (Buu and Kuchel, 1979). Therefore, these findings have two interesting implications for studies on TYR. First, the higher TH transcription activity associated with the $\mathrm{T}$ allele in the C-824T polymorphism could mean that low baseline DA individuals who carry this allele can benefit especially from TYR supplementation, as more TYR can be converted into DA. Second, the idea that the $T$ allele protects against cognitive decline in schizophrenia could imply that it does so in old age as well. In that case, the effect of this polymorphism on TYR supplementation might be strongest in older individuals, as might be the case with the DRD2 gene. This possibility again underscores the need to keep age and age-related changes in neurophysiology in mind when investigating TYR.

\section{CONCLUSION}

The amino-acid TYR is a promising cognitive enhancer, yet studies on how TYR supplementation can benefit cognitive performance are still scarce. We suggest that future studies on TYR should take into account individual differences related to DA function, and to that end we have listed several indicators and modulators of DA that could predict the effect of TYR supplementation. It should be noted that these factors are unlikely to operate independently from each other. For example, individuals carrying the Val allele of the COMT polymorphism, which indicates a low prefrontal DA level, could benefit especially from TYR when also carrying the $\mathrm{T}$ allele of the $\mathrm{TH}$ gene, since that would allow more conversion of TYR into DA. As such, interactions between the presently suggested modulators should be taken into account, to achieve a better understanding of their implications for the effect of TYR supplementation.

\section{ACKNOWLEDGMENTS}

This work was supported by research grant from the Netherlands Organization for Scientific Research (NWO) awarded to Lorenza S. Colzato (Vidi grant: \#452-12-001).

\section{REFERENCES}

Bäckman, L., Ginovart, N., Dixon, R. A., Wahlin, T. B., Wahlin, A., Halldin, C., et al. (2000). Agerelated cognitive deficits mediated by changes in the striatal dopamine system. Am. J. Psychiatry 157, 635-637. doi: 10.1176/appi.ajp.157.4.635

Bäckman, L., Nyberg, L., Lindenberger, U., Li, S.-C., and Farde, L. (2006). The correlative triad among aging, dopamine, and cognition: current status and future prospects. Neurosci. Biobehav. Rev. 30, 791-807. doi: 10.1016/j.neubiorev.2006.06.005

Baumeister, R. F., Bratslavsky, E., Muraven, M., and Tice, D. M. (1998). Ego depletion: is the active self a limited resource? J. Pers. Soc. Psychol. 74, 1252-1265. doi: 10.1037/0022-3514.74.5.1252

Bodis-Wollner, I., and Tzelepi, A. (1998). The pushpull action of dopamine on spatial tuning of the monkey retina: the effects of dopaminergic deficiency and selective D1 and D2 receptors ligands on the pattern electroretinogram. Vision Res. 38, 1479-1487. doi: 10.1016/S0042-6989(98) 00028-5

Buu, N. T., and Kuchel, O. (1979). The direct conversion of dopamine 3-0-sulfate to norepinephrine by dopamine- $\beta$-hydroxylase. Life Sci. $24,783-790$. doi: 10.1016/0024-3205(79)90361-8

Chen, J., Lipska, B. K., Halim, N., Ma, Q. D., Matsumoto, M., Melhem, S., et al. (2004). Functional analysis of genetic variation in catechol-O-methyltransferase (COMT): effects on mRNA, protein, and enzyme activity in postmortem human brain. Am. J. Hum. Genet. 75, 807-821. doi: 10.1086/425589

Colzato, L. S., Jongkees, B. J., Sellaro, R., and Hommel, B. (2013a). Working memory reloaded: tyrosine repletes updating in the N-back task. Front. Behav. Neurosci. 7:200. doi: 10.3389/fnbeh.2013.00200

Colzato, L. S., Jongkees, B. J., van den Wildenberg, W. P. M., and Hommel, B. (2014a). Eating to stop: tyrosine supplementation enhances inhibitory control but not response execution. Neuropsychologia 62, 398-402. doi: 10.1016/j. neuropsychologia.2013.12.027

Colzato, L. S., Sellaro, R., Hulka, L. M., Quednow, B. B., and Hommel, B. (2014b). Cognitive control predicted by color vision, and vice versa. Neuropsychologia 62, 55-59. doi: 10.1016/j. neuropsychologia.2014.07.010

Colzato, L. S., Slagter, H. A., Spapé, M. A., and Hommel, B. (2008a). Blinks of the eye predict blinks of the mind. Neuropsychologia 46, 3179-3183. doi: 10.1016/j.neuropsychologia.2008. 07.006

Colzato, L. S., van den Wildenberg, W. P. M., and Hommel, B. (2008b). Reduced spontaneous eye blink rates in recreational cocaine users: evidence for dopaminergic hypoactivity. PLoS ONE 2:e3461. doi: 10.1371/journal.pone.0003461

Colzato, L. S., van den Wildenberg, W. P. M., and Hommel, B. (2013b). The genetic impact (C957T-DRD2) on inhibitory control is magnified by aging. Neuropsychologia 51, 1377-1381. doi: 10.1016/j.neuropsychologia.2013.01.014

Colzato, L. S., van den Wildenberg, W. P. M., van der Does, A. J. W., and Hommel, B. (2010). Genetic markers of striatal dopamine predict individual differences in dysfunctional, but not function impulsivity. Neuroscience 170, 782-788. doi: 10.1016/j.neuroscience.2010.07.050
Colzato, L. S., van den Wildenberg, W. P. M., van Wouwe, N. C., Pannebakker, M. M., and Hommel, B. (2009). Dopamine and inhibitory action control: evidence from spontaneous eye blink rates. Exp. Brain Res. 196, 467-474. doi: 10.1007/s00221009-1862-x

Colzato, L. S., van Wouwe, N. C., and Hommel, B. (2007a). Feature binding and affect: emotional modulation of visuo-motor integration. Neuropsychologia 45, 440-446. doi: 10.1016/j. neuropsychologia.2006.06.032

Colzato, L. S., van Wouwe, N. C., and Hommel, B. (2007b). Spontaneous eyeblink rate predicts the strength of visuomotor binding. Neuropsychologia 45, 2387-2392. doi: 10.1016/j.neuropsychologia. 2007.03.004

Colzato, L. S., Zmigrod, S., and Hommel, B. (2013c). Dopamine, norepinephrine, and the management of sensorimotor bindings: individual differences in updating of stimulus-response episodes are predicted by DAT1, but not $\mathrm{DBH} 5^{\prime}$-ins/del. Exp. Brain Res. 228, 213-220. doi: 10.1007/s00221013-3553-x

Cools, R. (2006). Dopaminergic modulation of cognitive function-implications for L-DOPA treatment in Parkinson's disease. Neurosci. Biobehav. Rev. 30, 1-23. doi: 10.1016/j.neubiorev.2005.03.024

Cools, R., Frank, M. J., Gibbs, S. E., Miyakawa, A., Jagust, W., and D'Esposito, M. (2009). Striatal dopamine predicts outcome-specific reversal learning and its sensitivity to dopaminergic drug administration. J. Neurosci. 29, 1538-1543. doi: 10.1523/JNEUROSCI.4467-08.2009

Cools, R., Gibbs, S. E., Miyakawa, A., Jagust, W., and D’Esposito, M. (2008). Working memory capacity predicts dopamine synthesis capacity in the human striatum. J. Neurosci. 28, 1208-1212. doi: 10.1523/JNEUROSCI.4475-07.2008

Cuche, J. L., Prinseau, J., Selz, F., Ruget, G., Tual, J. L., Reingeissen, L., et al. (1985). Oral load of tyrosine or L-dopa and plasma levels of free and sulfoconjugated catecholamines in healthy men. Hypertension 7, 81-89. doi: 10.1161/01.HYP.7.1.81

Daubner, S. C., Le, T., and Wang, S. Z. (2011). Tyrosine hydroxylase and regulation of dopamine synthesis. Arch. Biochem. Biophys. 508, 1-12. doi: 10.1016/j.abb.2010.12.017

Deijen, J. B., and Orlebeke, J. F. (1994). Effect of tyrosine on cognitive function and blood pressure under stress. Brain Res. Bull. 33, 319-323. doi: 10.1016/0361-9230(94)90200-3

Deuschel, G., and Goddemeier, C. (1998). Spontaneous and reflex activity of facial muscles in dystonia, Parkinson's disease, and in normal subjects. J. Neurol. Neurosurg. Psychiatry 64, 320-324. doi: 10.1136/jnnp.64.3.320

Dreisbach, G., Müller, J., Goschke, T., Strobel, A., Schulze, K., Lesch, K., et al. (2005). Dopamine and cognitive control: the influence of spontaneous eyeblink rate and dopamine gene polymorphisms on perseveration and distractibility. Behav. Neurosci. 119, 483-490. doi: 10.1037/07357044.119.2.483

Duan, J., Wainwright, M. S., Comeron, J. M., Saitou, N., Sanders, A. R., Gelernter, J., et al. (2003). Synonymous mutations in the human dopamine receptor D2 (DRD2) affect mRNA stability and synthesis of the receptor. Hum. Mol. Genet. 12, 205-216. doi: 10.1093/hmg/ddg055 
Egan, M. F., Goldberg, T. E., Kolachana, B. S., Callicott, J. H., Mazzanti, C. M., Straub, D., et al. (2001). Effect of COMT Val108/158Met genotype on frontal lobe function and risk for schizophrenia. Proc. Natl. Acad. Sci. U.S.A. 98, 6917-6922. doi: 10.1073/pnas.111134598

Erixon-Lindroth, N., Farde, L., Wahlin, T. B., Sovago, J., Halldin, C., and Bäckman, L. (2005). The role of the striatal dopamine transporter in cognitive aging. Psychiatry Res. 138, 1-12. doi: 10.1016/j.pscychresns.2004.09.005

Freed, W. (1980). Eye-blink rates and platelet monoamine oxidase activity in chronic schizophrenic patients. Biol. Psychiatry 15, 329-332.

Gelenberg, A. J., and Gibson, C. J. (1984). Tyrosine for the treatment of depression. Nutr. Health 3, 163-173.

Gibson, C. J., and Wurtman, R. J. (1977). Physiological control of brain catechol synthesis by brain tyrosine concentration. Biochem. Pharmacol. 26, 1137-1142. doi: 10.1016/00062952(77)90057-0

Goldberg, T. E., and Weinberger, D. R. (2004). Genes and the parsing of cognitive processes. Trends Cogn. Sci. 8, 325-335. doi: 10.1016/j.tics.2004. 05.011

Goldman-Rakic, P. S., Muly, E. C., and Williams, G. V. (2000). D1 receptors in prefrontal cells and circuits. Brain Res. Rev. 31, 295-301. doi: 10.1016/S0165-0173(99)00045-4

Growdon, J. H., Melamed, E., Logue, M., Hefti, F., and Wurtman, R. J. (1982). Effects of oral L-tyrosine administration on CSF tyrosine and homovanillic acid levels in patients with Parkinson's disease. Life Sci. 30, 827-832.

Hirvonen, M. M., Laakso, A., Någren, K., Rinne, J. O., Pohjalainen, T., and Hietala, J. (2009b). C957T polymorphism of dopamine D2 receptor gene affects striatal DRD2 in vivo availability by changing the receptor affinity. Synapse 63, 907-912. doi: $10.1002 /$ syn.20672

Hirvonen, M. M., Lumme, V., Hirvonen, J., Pesonen, U., Någren, K., Vahlberg, T., et al. (2009a). C957T polymorphism of the human dopamine D2 receptor gene predicts extrastriatal dopamine receptor availability. Prog. Neuropsychopharmacol. Biol. Psychiatry 33, 630-636. doi: 10.1016/j.pnpbp.2009.02.021

Horiguchi, M., Ohi, K., Hashimoto, R., Hao, Q., Yasuda, Y., Yamamori, H., et al. (2014). Function polymorphism (C-824T) of the tyrosine hydroxylase gene affects IQ in schizophrenia. Psychiatry Clin. Neurosci. 68, 456-462. doi: 10.1111/pcn. 12157

Hulka, L. M., Wagner, M., Preller, K. H., Jenni, D., and Quednow, B. B. (2013). Blue-yellow color vision impairment and cognitive deficits in occasional and dependent stimulant users. Int. J. Neuropsychopharmacol. 16, 535-547. doi: $10.1017 /$ S1461145712000624

Karson, C. N. (1983). Spontaneous eye-blink rates and dopaminergic systems. Brain 106, 643-653. doi: 10.1093/brain/106.3.643

Lemoine, P., Robelin, N., Sebert, P., and Mouret, J. (1989). L-tyrosine: a long term treatment of Parkinson's disease. C. R. Acad. Sci. 309, 43-47.

Lewis, D., Melchitzky, D., Sesack, S., Whitehead, R., Auh, S., and Sampson, A. (2001). Dopamine transporter immunoreactivity in monkey cerebral cortex: regional, laminar, and ultrastructural localization. J. Comp. Neurol. 432, 119-136. doi: 10.1002/cne.1092

Li, S.-C., Papenberg, G., Nagel, I. E., Preuschhof, C., Schröder, J., Nietfeld, W., et al. (2013). Aging magnifies the effects of dopamine transporter and D2 receptor genes on backward serial memory. Neurobiol. Aging, 34, 358. doi: 10.1016/j. neurobiolaging.2012.08.001

Lindenberger, U., Nagel, I. E., Chicerio, C., Li, S.C., Heekeren, H. R., and Bäckman, L. (2008). Age-related decline in brain resources modulates genetic effects on cognitive functioning. Front. Neurosci. 2, 234-244. doi: 10.3389/neuro.01. 039.2008

Mahoney, C. R., Castellani, J., Kramer, F. M., Young, A., and Lieberman, H. R. (2007). Tyrosine supplementation mitigates memory decrements during cold exposure. Physiol. Behav. 92, 575-582. doi: 10.1016/j.physbeh.2007.05.003

Mattay, V. S., Goldberg, T. E., Fera, F., Hariri, A. R., Tessitore, A., Egan, M. F., et al. (2003). Catechol O-methyltransferase val158-met genotype and individual variation in the brain response to amphetamine. Proc. Natl. Acad. Sci. U.S.A. 100, 6186-6191. doi: 10.1073/pnas.0931309100

Miyake, A., Friedman, N. P., Emerson, M. J., Witzki, A. H., Howerter, A., and Wager, T. D. (2000). The unity and diversity of executive functions and their contributions to complex "frontal lobe" tasks: a latent variable analysis. Cogn. Psychol. 41, 49-100. doi: 10.1006/cogp.1999.0734

Muly, E. C. 3rd., Szigeti, K., and Goldman-Rakic, P. S. (1998). D1 receptor in interneurons of macaque prefrontal cortex: distribution and subcellular localization. J. Neurosci. 18, 10553-10565.

Nieoullon, A. (2002). Dopamine and the regulation of cognition and attention. Prog. Neurobiol. 67, 53-83. doi: 10.1016/S0301-0082(02)00011-4

Pieri, V., Diederich, N. J., Raman, R., and Goetz, C. G. (2000). Decreased color discrimination and contrast sensitivity in Parkinson's disease. J. Neurol. Sci. 172, 7-11. doi: 10.1016/S0022510X(99)00204-X

Rao, F., Zhang, L., Wessel, J., Zhang, K., Wen, G., Kennedy, B. P., et al. (2007). Tyrosine hydroxylase, the rate-limiting enzyme in catecholamine biosynthesis: discovery of common human genetic variants governing transcription, autonomic activity, and blood pressure in vivo. Circulation 116, 993-1006. doi: 10.1161/CIRCULATIONAHA.106. 682302

Roy, A., Roy, M., Berman, J., and Gonzalez, B. (2003). Blue cone electroretinogram amplitudes are related to dopamine function in cocainedependent patients. Psychiatry Res. 117, 191-195. doi: 10.1016/S0165-1781(02)00323-2

Shumay, E., Chen, J., Fowler, J. S., and Volkow, N. D. (2011). Genotype and ancestry modulate brain's DAT availability in healthy humans. PLOS ONE 6:e22754. doi: 10.1371/journal.pone.0022754
Shurtleff, D., Thomas, J. R., Schrot, J., Kowalski, K., and Harford, R. (1994). Tyrosine reverses a cold-induced working memory deficit in humans. Pharmacol. Biochem. Behav. 47, 935-941. doi: 10.1016/0091-3057(94)90299-2

Tannock, R., Banaschewski, T., and Gold, D. (2006). Color naming deficits and attentiondeficit/hyperactivity disorder: a retinal dopaminergic hypothesis. Behav. Brain Funct. 2:4. doi: 10.1186/1744-9081-2-4

Thomas, J. R., Lockwood, P. A., Singh, A., and Deuster, P. A. (1999). Tyrosine improves working memory in a multitasking environment. Pharmacol. Biochem. Behav. 64, 495-500. doi: 10.1016/S00913057(99)00094-5

van de Giessen, E., de Win, M. M. L., Tanck, M. W. T., van den Brink, W., Baas, F., and Booij, J. (2009). Striatal dopamine transporter availability associated with polymorphisms in the dopamine transporter gene SLC6A3. J. Nucl. Med. 50, 45-52. doi: 10.2967/jnumed.108.053652

van Spronsen, F. J., van Dijk, T., Smit, G. P. A., van Rijn, M., Reijngoud, D. J., Berger, R., et al. (1996). Large daily fluctuations in plasma tyrosine in treated patients with phenylketonuria. Am. J. Clin. Nutr. 64, 916-921.

Volkow, N. D., Fowler, J. S., Wang, G. J., Baler, R., and Telang, F. (2009). Imaging dopamine's role in drug abuse and addiction. Neuropharmacology 56, 3-8. doi: 10.1016/j.neuropharm.2008. 05.022

Volkow, N. D., Wang, G. J., Fowler, J. S., Ding, Y. S., Gur, R. C., Gatley, J., et al. (1998). Parallel loss of presynaptic and postsynaptic dopamine makers in normal aging. Ann. Neurol. 44, 143-147.

Witkovsky, P. (2004). Dopamine and retinal function. Doc. Ophthalmol. 108, 17-40. doi: 10.1023/B:DOOP.0000019487.88486.0a

Wood, D. R., Reimherr, F. W., and Wender, P. H. (1985). Amino acid precursors for the treatment of attention deficit disorder, residual type. Psychopharmacol. Bull. 21, 146-149.

Conflict of Interest Statement: The authors declare that the research was conducted in the absence of any commercial or financial relationships that could be construed as a potential conflict of interest.

Received: 21 July 2014; accepted: 11 September 2014; published online: 06 October 2014.

Citation: Jongkees BJ, Hommel B and Colzato LS (2014) People are different: tyrosine's modulating effect on cognitive control in healthy humans may depend on individual differences related to dopamine function. Front. Psychol. 5:1101. doi: 10.3389/fpsyg.2014.01101

This article was submitted to Cognition, a section of the journal Frontiers in Psychology.

Copyright (๑) 2014 Jongkees, Hommel and Colzato. This is an open-access article distributed under the terms of the Creative Commons Attribution License (CC BY). The use, distribution or reproduction in other forums is permitted, provided the original author(s) or licensor are credited and that the original publication in this journal is cited, in accordance with accepted academic practice. No use, distribution or reproduction is permitted which does not comply with these terms. 